El estudio destaca entre otras conclusiones, la existencia de grandes diferencias de salarios para un mismo oficio; diferencias en la ubicación de los trabajadores en las categorías ocupacionales de la empresa y muy distintos niveles de escolaridad en igualdad de salarios y ocupación. Dentro de esta situación los bachilleres industriales se dispersan dentro de la estructura de la empresa y la incorporación parece estar guiada más por el azar que por una lógica que prestara atención a un personal calificado por el sistema educativo para un mejor desempeño ocupacional.

Indudablemente, el estudio constituirá un valioso aporte a los planificadores de recursos humanos.

\title{
SEMINARIO INTERAMERICANO SOBRE NUCLEARIZACION Y REGIONALIZACION EDUCATIVA
}

Entre el 4 y 7 de noviembre del presente año, se realizó en Bogotá el Seminario Interamericano sobre Nuclearización y Regionalización Educativa, certamen al cual se hicieron presentes representantes de once países latinoamericanos: El Salvador, Nicaragua, Costa Rica, Guatemala, Panamá, Ecuador, Perú, Chile, Uruguay, Paraguay y Colombia y funcionarios del Instituto Centroamericano de Administración y Supervisión Educativa - ICASE-, del Centro Interamericano de Estudios e Investigaciones para el Planeamiento de la Educación —CINTERPLAN- y el Departamento de Asuntos Educativos de la OEA.

Este importante evento, producto de la Undécima Reunión del Consejo Interamericano para la Educación, la Ciencia y la Cultura (CIECC) realizada en julio de 1980, elaboró un programa conjunto de seminarios y pasantías que permitió conocer previamente en terreno por parte de los participantes, las experiencias de nuclearización y regionalización educativas en cada país e inmediatamente en el Seminario dar un tratamiento analítico y reflexivo a esta temática.

Reconociendo los principales problemas que a nivel latinoamericano se vienen presentando en el campo de la educación, como la necesidad de descentralizar el manejo administrativo, aumentar los niveles de retención escolar, mejorar los aspectos cualitativos en los programas de enseñanza, la capacitación docente, etc., atender a las desigualdades regionales contemplando los casos de mayor marginalidad y extrema pobreza, hacen partícipe a la población de los problemas y necesidades educativas, los programas de nuclearización apuntando a cada uno de ellos, han hecho énfasis en cada país en aspectos diferentes.

En el caso de NICARAGUA, la nuclearización se ha enfocado preferencialmente y como necesidad actual a la capacitación docente aprovechando la integración de centros docentes; en COSTA RICA el énfasis está dado hacia la educación curricular integrando a las unidades didácticas la problemática social económica; en ECUADOR el trabajo de organización y promoción de la comunidad cobra la mayor importancia y en COLOMBIA la descentralización administrativa a nivel de base asume el factor central.

En el campo de la Regionalización, la experiencia chilena fue presentada como una respuesta a las necesidades detectadas por el Mapa de extrema pobreza y como un planteamiento novedoso de descentralización administrativa a través de las municipalidades. 
Los propósitos del Seminario hacían referencia a la necesidad de intercambiar experiencias entre los diferentes modelos de nuclearización y presentar aspectos susceptibles de educación y utilización en los diferentes países, determinar los logros y dificultades encontradas en el tiempo de implantación de los programas, y analizar la nuclearización como instrumento de regionalización educativa.

En tal sentido las condiciones de este Seminario, permitieron integrar una definición general básica sobre la Nuclearización, como una estrategia o proceso a través del cual se constituyen los núcleos educativos para lograr el desarrollo educativo a nivel de base con la participación de la comunidad, sustentada en la descentralización, de tal manera, que genere soluciones a la problemática educativa y de Núcleo como una unidad operativa base del sistema educativo integrado por una red de centros y agentes educativos dentro de un ámbito territorial determinado; para administrar y planificar técnicamente la educación a nivel local con la participación de la comunidad.

Al relacionar la nuclearización y regionalización como los procesos de planificación educativa, se concluyó que ésta debe estar enmarcada e integrada a la planificación del desarrollo global o nacional y como subsistema debe ajustarse a las características propias del sector educativo. Igualmente, debe estar articulada internamente a sus respectivos niveles de gestión y en sus modalidades y niveles de enseñanza; además, de dar coherencia a los aspectos cualitativos como los cuantitativos.

La planificación educativa debe incorporar todos los aspectos de la educación formal y no formal, sea ésta ejecutada por el sector educación, u otros sectores en que se divide la administración pública e iniciativa privada.

Al analizar la incidencia de la nuclearización y regionalización en la administración educativa, se observa que éstas presentan algunas ventajas como:

-Permitir la agilización de la administración en cuanto a la prestación del servicio educativo.

-Promover la participación y concentración de las diferentes instancias educativas e intersectoriales que operan en la región y la localidad.

- Tener en cuenta las características propias de la región o localidad en términos de sus necesidades.

-Estimular la iniciativa tendiente al autodesarrollo regional y local.

—Mejorar el flujo migracional.

De otra forma, contiene algunas limitaciones y dificultades como:

—El temor de los agentes centrales a la pérdida de poder. islas.

—Una posible atomización del sector si las regiones o los núcleos se convierten en

- La escasez de recursos de diferente índole en algunas regiones: personal calificado, bajo presupuesto, etc. 
En cuanto a la participación e integración comunitaria en el marco de la nuclearización se resalta que:

- La participación de la comunidad debe ser independiente de intereses externos, esto es que tenga libertad para manifestarse.

-El papel del sistema educativo en el desarrollo comunitario como dinamizador del cambio sólo podrá hacerse realidad en la medida en que el currículo será reflejo-del conocimiento objetivo de la realidad política, económica, social y cultural del país.

Destacar sólo estas conclusiones, deja de lado un material muy rico en observaciones y experiencias de un evento que marca un hito importante en el conocimiento de la problemática educativa latinoamericana y que de manera novedosa salió de los esquemas convencionales de reuniones de altas autoridades educativas, para incorporar en esta actividad a los ejecutores y dinamizadores de la nuclearización y regionalización educativa en distintos contextos geográficos y políticos de la región. 